\title{
Influence of High-Dose Pancreatic Enzyme Treatment on Pancreatic Function in Healthy Volunteers
}

\author{
Helmut Friess, ${ }^{1}$ Jörg Kleeff, ${ }^{1}$ Peter Malfertheiner, ${ }^{2}$ \\ Michael W. Müller, ${ }^{3}$ Kaiken Homuth, ${ }^{1}$ and Markus W. Büchler*,I \\ ${ }^{I}$ Department of Visceral and Transplantation Surgery, University of Bern, Switzerland; \\ ${ }^{2}$ Department of Gastroenterology, Hepatology and Infectious Disease, Otto von Guericke University, \\ Magdeburg, Germany; ${ }^{3}$ Department of Surgery, University of Ulm, Germany
}

\begin{abstract}
Summary
Conclusions. Adaptive changes in exocrine and endocrine pancreatic function, as well as changes in pancreas size and morphology, were not observed after $4 \mathrm{wk}$ of oral pancreatic enzyme application. These findings suggest that the normal pancreas does not significantly adapt—either morphologically or functionally - to a 4-wk oral application of high-dose pancreatic enzymes.

Background. The control of exocrine pancreatic enzyme secretion is not completely understood. Although it has been established that exocrine pancreatic secretion is mainly regulated in the short-term by the amount of pancreatic enzymes in the proximal small intestine, it is not known whether long-term application of pancreatic enzymes causes changes in exocrine pancreatic secretion in humans.

Methods. Twelve healthy male volunteers (median age $27 \mathrm{yr}$ ) participated in a prospective, randomized, placebo-controlled, double-blind study. Six were placed in the treatment group and six in the placebo group. Over a 4-wk period, the six subjects in the treatment group took 18 capsules of Panzytrat (20,000 units of lipase, 18,000 units of amylase, and 1000 units of protease per capsule) daily. Before (wk 0), 4 wk following pancreatic enzyme application and $2 \mathrm{wk}$ afterward, a secretin-cerulein test was carried out in all subjects to study exocrine pancreatic function (trypsin, chymotrypsin, bicarbonate content, and total pancreatic fluid secretion in the duodenum). One day following the secretin-cerulein test, a standard test meal was given to all subjects to analyze endocrine pancreatic function. Additionally, before starting the treatment, once per week during treatment and $2 \mathrm{wk}$ afterward, an ultrasound examination of the pancreas was carried out to see whether there was any change in pancreas size and morphology.

Results. Trypsin content in the duodenal aspirates following simultaneous stimulation with secretin and cerulein after 4 wk of high-dose pancreatic enzyme application was $92 \%$ in the treatment group and $82 \%$ in the placebo group compared with the wk 0 test results (100\%). Two weeks after enzyme application, the secretin/cerulein-stimulated trypsin content was $88 \%$ in the treatment group and $107 \%$ in the placebo group. None of these changes was statistically significant. The same results were seen for chymotrypsin content, amylase, and bicarbonate content as well as for total pancreatic fluid secretion. Additionally, no change in the endocrine pancreatic function could be observed after $4 \mathrm{wk}$ of pancreatic enzyme treatment. Pancreas ultrasonography revealed no alteration in pancreas size or parenchymal structure during the $4 \mathrm{wk}$ of treatment and the following $2 \mathrm{wk}$.
\end{abstract}

Key Words: Pancreas; enzyme treatment; exocrine function; feedback regulation.

Received June 23, 1997; Revised and Accepted November 10, 1997.

*Author to whom all correspondence and reprint requests should be sent: Department of Visceral and Transplantation Surgery, University of Bern, Inselspital, CH-3010 Bern, Switzerland. 


\section{Introduction}

The exocrine pancreas secretes an alkaline enzymerich fluid, which is needed to effect the major digestive activity of the gastrointestinal tract. From several studies we have learned that exocrine pancreatic secretion is under both hormonal and neural control: Cholecystokinin, an intestinal hormone, evokes an enzyme-rich secretion from the pancreas, and the vagus nerve, as a part of the parasympathetic nervous system, also exerts some control over pancreatic secretion (1-6).

Although it has been well established from studies in animals (7-13) that the presence of pancreatic enzymes (trypsin, chymotrypsin) in the proximal small intestine causes a negative feedback regulation on pancreatic enzyme secretion, the findings in humans remain controversial. Though most studies demonstrate a negative feedback control of pancreatic enzyme secretion regulated by trypsin (14-18) and mediated by the release of the intestinal hormone cholecystokinin (1), other studies conversely report that inhibition of intestinal trypsin does not stimulate exocrine pancreatic secretion $(19,20)$. However, most of these studies focus on short-term effects of the feedback regulation, and little is known about long-term feedback mechanisms and adaptive changes of exocrine and endocrine pancreatic secretion in humans.

In a subgroup of patients with chronic pancreatitis and mild-to-moderate exocrine pancreatic insufficiency, it could be demonstrated that oral pancreatic enzyme application decreases abdominal pain (21-27). These observations seem to fit with data in humans that demonstrate a negative feedback regulation for pancreatic exocrine secretion controlled by the amount of trypsin in the upper small intestine. However, these reports were only clinical observations in a selected number of patients with chronic pancreatitis.

Under the assumption that, in humans, a negative feedback mechanism exists, which is controlled by the content of pancreatic enzymes in the upper small bowel, high-dose pancreatic enzyme application during eating should diminish food-induced pancreatic enzyme secretion. This expected downregulation of pancreatic enzyme secretion could lead to a decrease in pancreatic enzyme synthesis and thereby to a functional adaptation of pancreatic parenchyma.
Therefore, the aim of our prospective, randomized, placebo-controlled, double-blind study was to investigate the effects of a 4-wk high-dose pancreatic enzyme application on exocrine and endocrine pancreatic function, as well as on the pancreas size and morphology in humans.

\section{Methods}

\section{Subjects}

Twelve healthy male volunteers (medical students), 23-33 yr old (median age $27 \mathrm{yr}$ ), participated in this study. All subjects were within $\pm 10 \%$ of their ideal body wt, none were taking medication, and none had any history of previous pancreatic or nonpancreatic gastrointestinal disease. The subjects were randomly assigned to the treatment or the placebo group in a double-blind fashion in the order in which written informed consent was given. The study protocol was approved by the University ethical committee.

\section{Medication}

Panzytrat (Nordmark, Uetersen, Germany) is an acid-resistant microcapsule containing pig pancreatin, which consists of 20,000 units triacylglycerollipase, 18,000 units amylase, and 1000 units protease. The placebo capsules were identical to the panzytrat medication, except that no pancreatic enzymes were added to the vehicle.

\section{Procedures}

According to the study design (prospective, randomized, placebo-controlled, double-blind), the subjects took 18 oral capsules of either Panzytrat or the placebo daily over a 4-wk period. During the study, the subjects ate breakfast and lunch with six capsules of Panzytrat (one capsule 10 min before the meal, four capsules during the meal, and one capsule $10 \mathrm{~min}$ after the meal), and they ate dinner and one betweenmeal snack with three capsules of Panzytrat (one capsule 10 min before, one capsule during, and one capsule 10 min after the meal) daily. Before the study (wk 0), at the end of $4 \mathrm{wk}$ of pancreatic enzyme application (wk 4), and 2 wk after the end of the pancreatic enzyme substitution (wk 6), a secretincerulein test was carried out in all subjects to measure the exocrine pancreatic secretion (amylase, trypsin, chymotrypsin, bicarbonate, and total pan- 
creatic fluid volume). At the same time, blood samples were obtained to measure amylase and lipase serum activity.

In addition, $1 \mathrm{~d}$ following the secretin-cerulein test, a standard test meal was given to analyze changes in the secretion of the pancreatic islet hormones insulin and glucagon as well as to measure changes in the blood glucose levels.

Before pancreatic enzyme treatment, once each week during treatment, and once per week in the first 2 wk after treatment, an ultrasound examination of the pancreas was carried out to see whether there was any change in the size and structure of the pancreas. Furthermore, during the period of study medication, the volunteers completed a questionnaire to ensure that the study medication was taken regularly and according to the study protocol.

Additionally, the daily calorie intake as well as the body weight of each subject was registered during the test period using an alimentation diary to ensure no excess calorie intake.

\section{Secretin-Cerulein Test}

At study wk 0, 4, and 6, duodenal aspirates were sampled with a double-lumen catheter, which was placed in the duodenum under X-ray control, with its tip at the papilla Vateri and the second opening in the stomach.

The test started with duodenal aspiration in 10-min intervals for $30 \mathrm{~min}$ during the baseline phase. Aspiration in 10-min intervals was performed for $60 \mathrm{~min}$ after bolus injection of secretin $(1 \mathrm{U} / \mathrm{kg})$ and for 60 min during continuous infusion of secretin ( $1 \mathrm{U} / \mathrm{kg} / \mathrm{h}$ ) and cerulein $(80 \mathrm{ng} / \mathrm{kg} / \mathrm{h})$. Duodenal aspirates were collected on ice and assayed immediately for trypsin, chymotrypsin, amylase, bicarbonate, and total volume. During the secretin-cerulein test, blood samples were obtained at 15, 30, 60, 90, 120 , and $150 \mathrm{~min}$ to measure serum amylase and lipase activity.

\section{Standard Test Meal}

After an overnight fast of $10 \mathrm{~h}$, all subjects were given a liquid standard test meal $1 \mathrm{~d}$ after the secretin-cerulein test (study wk 0, 4, and 6). The test meal consisted of $500 \mathrm{~mL} \mathrm{H}_{2} \mathrm{O}, 5 \mathrm{~mL}$ thistle oil, and $130 \mathrm{~g}$ $(2126$ kJ) Meriten (Sandoz-Wander AG, Bern, Switzerland) containing $73.3 \mathrm{~g}$ carbohydrate, $39.6 \mathrm{~g}$ protein, and $5.72 \mathrm{~g}$ fat. One minute before the test meal and $1,3,5,10,15,30,45,60,75,90,120,150$, and $180 \mathrm{~min}$ afterward, blood samples were taken and mixed with an EDTA-trasylol solution (Bayer AG, Leverkusen, Germany; $750 \mathrm{mg}$ EDTA in $50 \mathrm{~mL}$ aprotinin, ratio 1:10). The blood sugar and the islet cell hormones insulin and glucagon were measured in these plasma samples.

\section{Ultrasonography}

In wk $0,1,2,3,4,5$, and 6 of the study, an ultrasonography of the pancreas was performed, with special attention paid to the size and structure of the pancreas. The sizes of the head (oblique and vertical diameter), the body (vertical diameter), and the tail (vertical diameter) of the pancreas were measured as well as the size of the main pancreatic duct if visualizable.

\section{Pancreatic Enzyme Analysis of the Duodenal Aspirates}

Trypsin was measured by the hydrolysis of tosylL-arginin methylester, chymotrypsin by the hydrolysis of $n$-benzoyl-L-tyrosinester, amylase by reduction of 3.5-dinitro-salicylic acid, and bicarbonate by a titrimetric method, as previously reported (28-30).

\section{Blood Glucose, Serum Amylase, and Lipase Measurement}

The blood glucose concentration was measured by the glucose dehydrogenase method (Granutest, Merck, Darmstadt, Germany) in an automatic analyzer (Eppendorf, Hamburg, Germany). Serum amylase and lipase were measured by hydrolysis of 3 p-nitrophenylmaltoheptasoid and triolin, respectively, in an automatic analyzer (Boehringer Mannheim, Mannheim, Germany).

\section{Hormone Analysis}

Plasma insulin concentration was measured with the commercial insulin radioimmunoassay kit SB-INSI-I (Sorin Biomedic, Italy). The sensitivity was $0.082 \mathrm{ng} / \mathrm{mL}$, the interassay variance was $2.8 \%$, and the intra-assay variance was $8.6 \%$.

The glucagon serum plasma concentration was measured with a radioimmunoassay using the glucagon antiserum K30 (kind gift of Roger Unger, University of Texas, Dallas, TX) and Indium 125 -labeled glucagon. The interassay variance and the intraassay variance of the glucagon radioimmunoassay were 14 and $9 \%$, respectively. 


\section{Statistical Analysis}

The results are expressed as mean \pm standard error of mean (SEM). For statistical analysis, the Student $t$-test was used. Significance was defined as $p<0.05$.

\section{Results}

\section{Comparison of Groups}

The subjects were randomly distributed between the treatment and placebo groups. The groups were comparable with regard to subjects' age, gender, body weight, and daily calorie intake, and there was no change in the subjects' body weight and daily calorie intake during the $4 \mathrm{wk}$ of pancreatic enzyme application and $2 \mathrm{wk}$ afterward.

No statistically significant difference could be detected in any test carried out before enzyme medication was started (wk 0).

\section{Side Effects}

There were weekly assessments of serum sodium, potassium, ALT, AST, GGT, PT, PTT, creatinine, and BUN in all subjects. Before, during, and 2 wk after the test period, no subject showed any abnormality.

None of the subjects suffered from severe side effects. Two subjects in the treatment group complained of mild nausea, epigastric pain, and heartburn. These symptoms disappeared spontaneously, and none led to termination of participation in the study.

\section{Exocrine Pancreas Secretion}

All test results were compared with the test results obtained before the pancreatic enzyme application was started (wk 0). At wk 0, all subjects had normal exocrine pancreatic function as determined by the secretin-cerulein test.

\section{Trypsin}

Following bolus stimulation with secretin $(1 \mathrm{U} / \mathrm{kg})$, the duodenal trypsin content after 4 wk of high-dose enzyme application was $83 \%$ in the treatment and $73 \%$ in the placebo group, compared with the wk 0 test results (100\%). Two weeks after the end of highdose enzyme application, the duodenal trypsin content following secretin stimulation was $87 \%$ in the treatment group and $79 \%$ in the placebo group, compared with the wk 0 test results. The trypsin content following continuous simultaneous stimulation with trypsin - secretin+cerulein stimulation

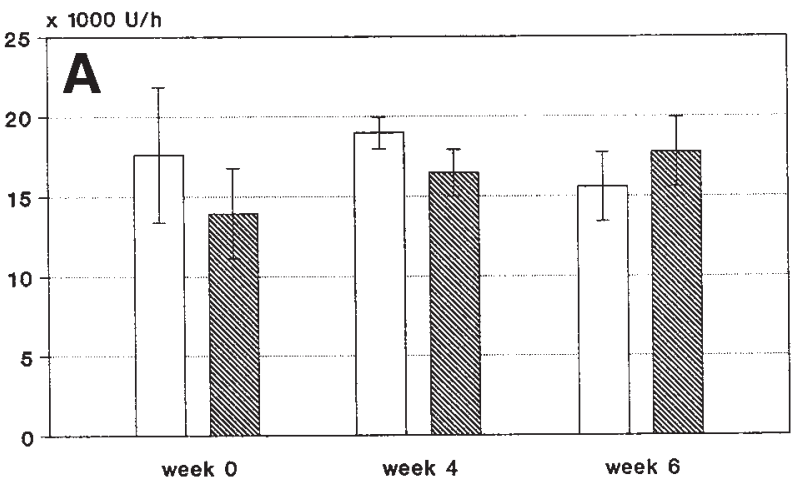

chymotrypsin - secretin + cerulein stimulation

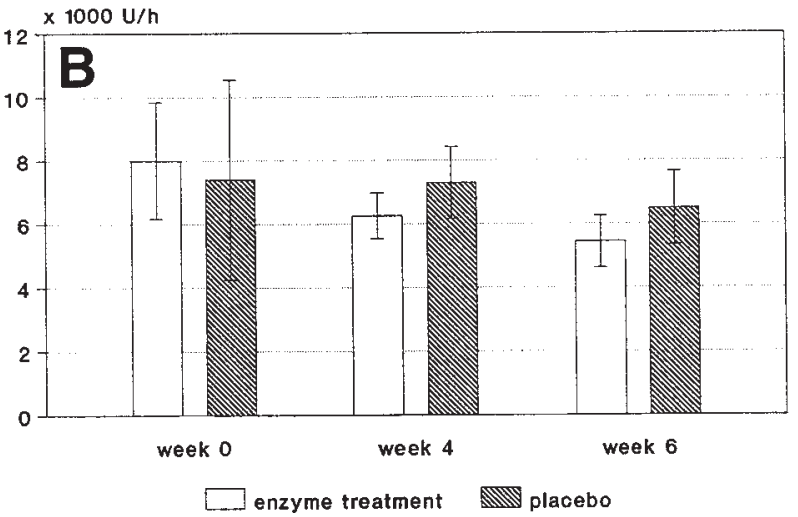

Fig. 1. Exocrine pancreatic function analyzed with the secretin-cerulein test before pancreatic enzyme application (wk 0), following 4 wk of pancreatic enzyme application (wk 4), and 2 wk after the end of pancreatic enzyme application (wk 6). Cumulative pancreatic secretion of trypsin (A) and chymotrypsin (B) after continuous infusion of secretin $(1 \mathrm{U} / \mathrm{kg} / \mathrm{h})$ and cerulein $(80 \mathrm{ng} / \mathrm{kg} / \mathrm{h})$ in the placebo and treatment groups. Values are mean \pm SEM.

secretin and cerulein was $92 \%$ in the treatment group and $82 \%$ in the placebo group after 4 wk of high-dose enzyme application (Fig. 1). Two weeks after the end of high-dose enzyme application, the duodenal trypsin content following continuous simultaneous stimulation with secretin and cerulein was $88 \%$ in the treatment group and $107 \%$ in the placebo group, compared with the wk 0 test results (Fig. 1). None of these changes in the trypsin content-neither between the different tests at wk 0,4 , and 6 , nor between the treatment and placebo groups - was statistically significant. 


\section{Chymotrypsin}

Chymotrypsin showed a pattern comparable to that of trypsin. There were no statistically significant changes in the chymotrypsin content at the different test dates between the treatment and the placebo groups: The chymotrypsin content after stimulation with secretin was 59\% (treatment group) and 71\% (placebo group) after 4 wk of high-dose enzyme application and 54\% (treatment) and 63\% (placebo) $2 \mathrm{wk}$ after the end of high-dose enzyme application. Following continuous simultaneous stimulation with secretin-cerulein, the chymotrypsin content was $78 \%$ (treatment) and $85 \%$ (placebo) after 4 wk of high-dose enzyme application and $68 \%$ (treatment) and $78 \%$ (placebo) $2 \mathrm{wk}$ after the end of enzyme application (wk 6) (Fig. 1).

\section{Amylase}

Following stimulation with secretin, the duodenal amylase content at wk 4 was $86 \%$ in the treatment group and $77 \%$ in the placebo group and at wk 6 was $77 \%$ in the treatment group and $70 \%$ in the placebo group, compared with the results before enzyme application at wk 0. Following continuous stimulation with secretin and cerulein, the duodenal amylase content at wk 4 was $107 \%$ in the treatment group and $91 \%$ in the placebo group. At wk 6, 2 wk after the end of enzyme application, duodenal amylase content was $102 \%$ in the treatment group and $106 \%$ in the placebo group. Again, none of these changes was statistically significant.

\section{Bicarbonate}

The duodenal bicarbonate content following stimulation with secretin was $94 \%$ (treatment) and $104 \%$ (placebo) at wk 4 and $76 \%$ (treatment) and 93\% (placebo) at wk 6. Duodenal bicarbonate content following continuous stimulation with secretin and cerulein was $81 \%$ (treatment) and $109 \%$ (placebo) at wk 4 and $93 \%$ (treatment) and $108 \%$ (placebo) at wk 6 (Fig. 2). None of these changes in the duodenal bicarbonate content was statistically significant.

\section{Total Pancreatic Volume Secretion}

The total pancreatic juice vol secretion after bolus stimulation with secretin was $94 \%$ (treatment) and $103 \%$ (placebo) at wk 4 and $84 \%$ (treatment) and $101 \%$ (placebo) at wk 6. After simultaneous stimulation with secretin and cerulein, the total secretion was $97 \%$ (treatment) and 104\% (placebo) at wk 4 and $90 \%$ (treatment) and $100 \%$ (placebo) at wk six (Fig. 2). None of the changes was significant.

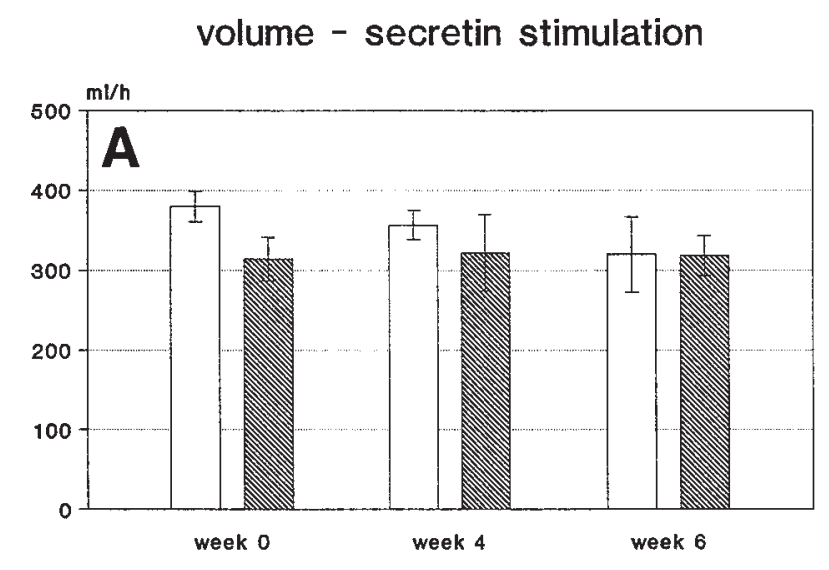

\section{bicarbonate - secretin stimulation}

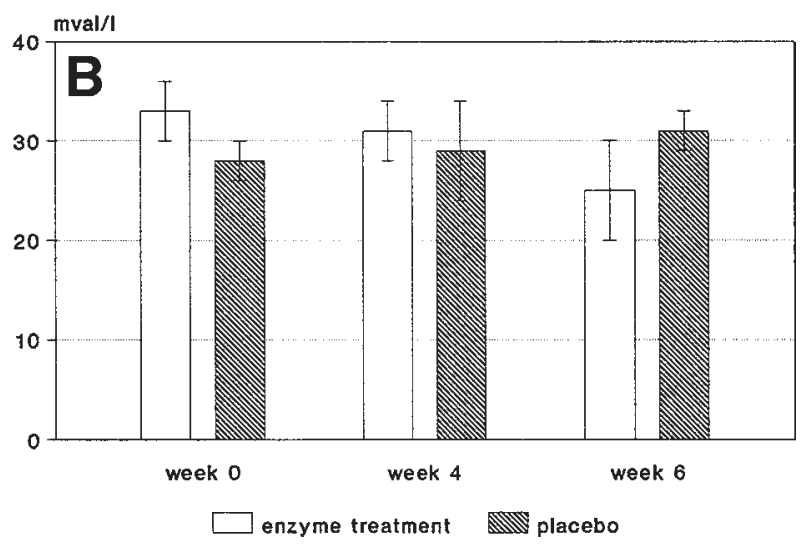

Fig. 2. Exocrine pancreatic function analyzed with the secretin-cerulein test before pancreatic enzyme application (wk 0), following 4 wk of pancreatic enzyme application (wk 4), and $2 \mathrm{wk}$ after the end of the pancreatic enzyme application (wk 6). Cumulative pancreatic total volume fluid secretion (A) and bicarbonate secretion (B) after bolus application of secretin $(1 \mathrm{U} / \mathrm{kg})$ in the placebo and treatment groups. Values are mean \pm SEM.

\section{Serum Lipase and Amylase}

Lipase and amylase activity in the serum before and after the secretin test and after the secretincerulein stimulation at 0,4 , and 6 wk showed no statistically significant difference, either between the treatment and placebo groups or among the results at 0,4 , and $6 \mathrm{wk}$.

\section{Endocrine Pancreatic Secretion}

\section{Insulin}

Plasma insulin levels showed a peak 30 min after application of the standard test meal and had decreased 

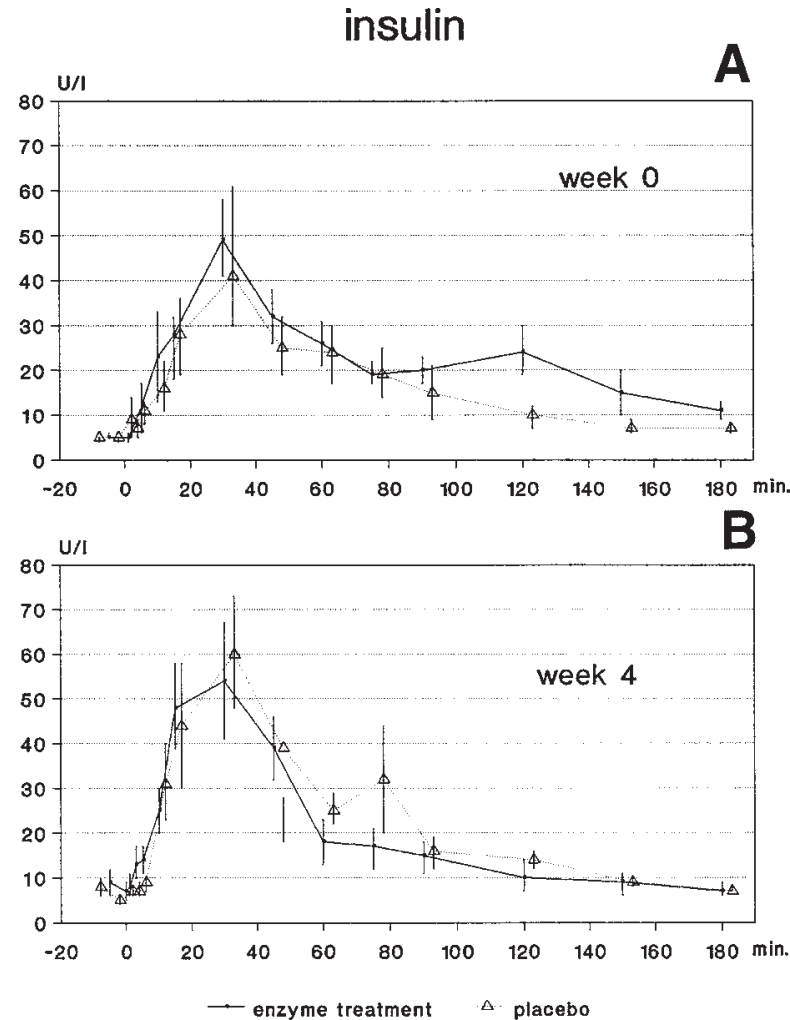

Fig. 3. Endocrine pancreatic function analyzed by application of a standard test meal. Baseline and postprandial insulin levels before pancreatic enzyme application (wk 0) (A) and following 4 wk of pancreatic enzyme application (wk 4) (B) in the placebo and treatment groups. Values are mean \pm SEM.

to the baseline concentration by around $180 \mathrm{~min}$. There were no statistically significant differences, either between the treatment and placebo groups or among the test meals at 0, 4, and 6 wk (Fig. 3).

\section{Glucagon}

Following application of the standard test meal, plasma glucagon levels increased during the first 10 min and remained constant afterward. No significant changes could be observed between the treatment and placebo groups at wk 0,4 , and 6 (Fig. 4).

\section{Blood Glucose}

There were no statistically significant changes in the physiologic response of the blood glucose levels to the test meals between the treatment and placebo groups at the different test times.

\section{glucagon}
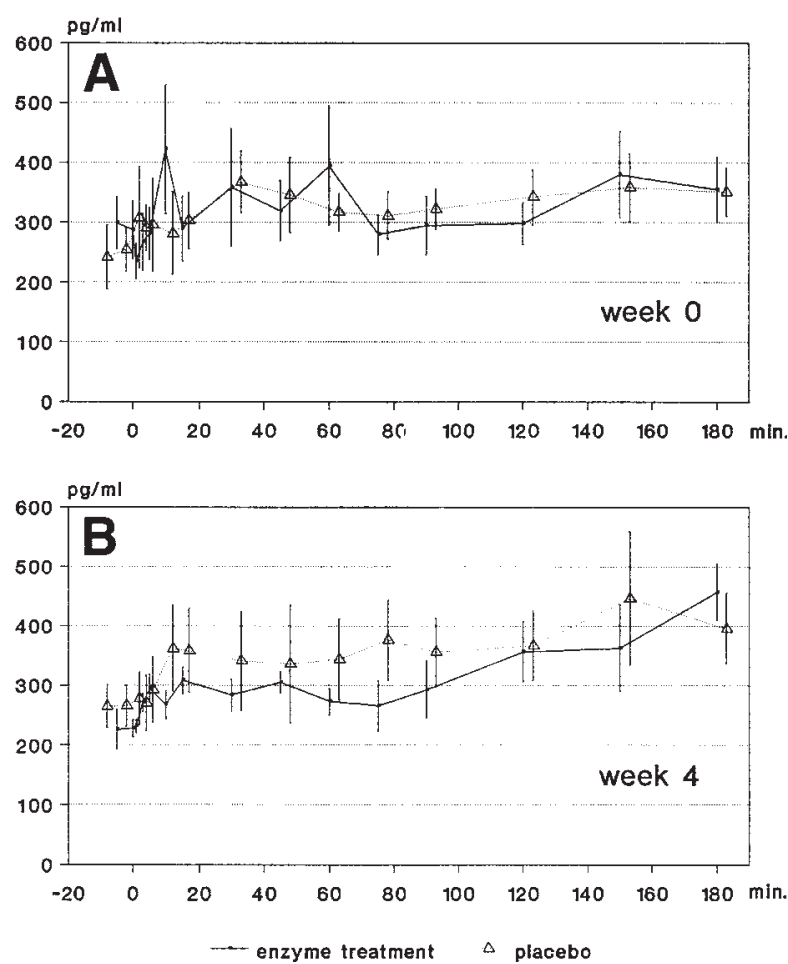

Fig. 4. Endocrine pancreatic function analyzed by application of a standard test meal. Baseline and postprandial glucagon levels before pancreatic enzyme application (wk 0) (A) and following 4 wk of pancreatic enzyme application (wk 4) (B) in the placebo and treatment groups. Values are mean \pm SEM.

\section{Ultrasonography of the Pancreas}

There was no significant increase or decrease in the size of the head, the body, or the tail of the pancreas, nor any observable change in the structure of the pancreas, when the treatment and placebo groups were compared before, during, and $2 \mathrm{wk}$ after the pancreatic enzyme application.

\section{Discussion}

A number of in vivo and in vitro studies in animals demonstrate a negative feedback regulation of the exocrine pancreas secretion by pancreatic enzymes in the upper small intestine (7-13,31-33). Several studies have found a feedback inhibition of pancreatic secretion in man, regulated by trypsin (14-18,34-36) and mediated by cholecystokinin $(1,37)$. However, 
other studies have failed to demonstrate a stimulation of pancreatic secretion by inhibition of trypsin $(19,20)$, as would be expected with this model.

In this study, we demonstrated that exocrine pancreatic secretion, stimulated by secretin and cholecystokinin, was not altered by oral application of high dosages of pancreatic enzymes. Moreover, there was no inhibition of the bicarbonate secretion and the total volume of pancreatic secretion. Also, there was no change in the lipase and amylase activity in the serum. However, other studies-focusing on short-term effects-provide strong support for the theory that feedback regulation of pancreatic enzyme secretion operates in man $(14,15)$. Owyang et al. (14) demonstrated in a dose response study of 12 healthy individuals that the minimal concentration of trypsin in the duodenum required to inhibit pancreatic secretion was $0.5 \mathrm{~g} / \mathrm{L}$, and that maximal suppression was observed with $1 \mathrm{~g} / \mathrm{L}$. The suppression seemed to be enzyme-specific, since suppression was not observed with intraduodenal perfusion of lipase or amylase. Furthermore, double-blind trials have demonstrated that pancreatic enzyme application may decrease the abdominal pain in selected patients with chronic pancreatitis (21-27,38). Slaff et al. (26) could show that oral pancreatic extract administration decreased abdominal pain in chronic pancreatitis patients, and that intraduodenal perfusion with proteases suppressed exocrine secretion in those patients. Additionally, they were able to demonstrate a significant decrease in basal and stimulated chymotrypsin output after $30 \mathrm{~d}$ of oral pancreatic extract treatment. However, these results were obtained only in a small subgroup of three patients with chronic pancreatitis. These clinical observations seem to fit in with other studies in man that demonstrate a negative feedback regulation for pancreatic enzyme secretion controlled by the concentration of trypsin in the upper small intestine. Liener et al. (18) could clearly show such a negative feedback control of exocrine pancreatic secretion. Administration of a trypsin/chymotrypsin inhibitor (Bowman-Birk) significantly increased pancreatic output and concentration of trypsin, chymotrypsin, elastase, and amylase, indicating that the human pancreas is responsive to intraduodenally administered protease inhibitors. However, such short-term experiments do not reveal the physiologic consequences that might accompany long-term protease inhibitor or pancreatic enzyme ingestion.
The hypothesis of our study was that with high doses of oral pancreatic enzyme application, endogenous pancreatic enzyme secretion is reduced. We hypothesized that the application of high-dose pancreatic enzymes during food uptake would abolish or significantly reduce food-induced pancreatic enzyme secretion and thereby down-regulate pancreatic enzyme synthesis in the acinar cells. This in turn would lead to pancreatic atrophy and nonadequate response to endogenous- or exogenousinduced pancreatic enzyme secretion.

The following mechanisms may be responsible for our failure to detect changes in pancreatic enzyme secretion following the application of pancreatic enzymes over $4 \mathrm{wk}$ :

1. The concentration of enzymes given in the study was too low to inhibit food-induced pancreatic secretion.

2. The enzyme preparation used does not contain trypsin. As mentioned above, there seems to be a minimal trypsin concentration in the duodenum necessary to exert inhibition of pancreatic enzyme secretion, and the suppression seems to be enzymespecific. Trypsin inhibits pancreatic secretion, whereas lipase and amylase do not (26).

3. The secretin and cholecystokinin analog used in the secretin-cerulein test could have evoked a maximal response of the exocrine pancreatic secretion, thereby masking the inhibitory effect of orally administered pancreatic enzymes on pancreatic secretion.

4. Because only stimulated pancreatic secretion was tested, no certain conclusion could be drawn concerning the effect of high-dose pancreatic enzyme application on interdigestive pancreatic enzyme secretion.

In the present study, no statistically significant difference could be detected in the endocrine pancreatic function, as determined with the application of a standard test meal at three time points: before high-dose pancreatic enzyme treatment, after $4 \mathrm{wk}$ of treatment, and $2 \mathrm{wk}$ after the end of treatment. The endocrine pancreas (islet cells) and the exocrine pancreas are anatomically closely related, so that, for example, inflammation may affect the endocrine as well as the exocrine pancreas. However, the regulation of exocrine pancreatic secretion seems to be independent of endocrine pancreatic secretion, and 
much is known about the feedback mechanisms of the various islet cell hormones. Thus it is not surprising that there have been no studies investigating the regulatory effect of exocrine pancreatic enzymes on endocrine pancreatic function. As expected, our study could not demonstrate any significant changes in the serum insulin, glucagon, or blood glucose concentrations as a result of 4 wk of pancreatic enzyme application.

In this study, we were able to demonstrate by ultrasonography that pancreas size and parenchymal structure are not altered during 4 wk of high-dose pancreatic enzyme treatment. This might be a result of limitations in the sensitivity of ultrasonography to detect minor morphological changes in the pancreas. However, only young, healthy volunteers were included in our study, and the analysis of pancreatic morphology by contrast-enhanced computed tomography was not possible because of radiation exposure.

Lee et al. (39) found hypertrophic changes in the rat pancreas in the presence of high-serum cholecystokinin concentration. Similarly, Solomon et al. $(32,33)$ showed that chronic administration of exogenous cholecystokinin to rats has a marked trophic effect on the pancreas; however, they conversely reported that the administration of cerulein to dogs for as long as $2 \mathrm{wk}$ had no trophic effect on the pancreas. These findings indicate that adaptive changes of the pancreas in response to exogenous hormone application might be species-specific. The present study in humans - the first to our knowledgeshowed no change in the size and morphology of the pancreas during $4 \mathrm{wk}$ of high-dose oral pancreatic enzyme application and $2 \mathrm{wk}$ afterward.

There are several possible explanations for this result. First, it is possible that the human pancreas does not adapt to exogenous enzyme application. Second, perhaps we were not able to detect adaptive pancreatic changes by ultrasonography. And third, it could have been that the time schedule of enzyme application and the dosage of enzymes were not sufficient to induce changes in the size and morphology of the human pancreas.

Most studies focus on the short-term effect of pancreatic feedback regulation, whereas the study presented here is the first that investigates the effects of $4 \mathrm{wk}$ of pancreatic enzyme application on pancreatic function in healthy volunteers. With our study design, we could not detect morphological and func- tional changes after $4 \mathrm{wk}$ of oral pancreatic enzyme application. No statistically significant effect on the exocrine and endocrine pancreatic function or on the pancreas size and structure were observed.

\section{Acknowledgment}

This study was supported by a research grant from Nordmark, Uetersen, Germany.

\section{References}

1 Adler G, Beglinger C, Braun K, et al. Interaction of the cholinergic system and cholecystokinin in the regulation of endogenous and exogenous stimulation of pancreatic secretion in humans. Gastroenterology 1991; 100:537-543.

2 Adler G, Müllenhoff A, Koop I, et al. Stimulation of pancreatic secretion in man by a protease inhibitor. Eur $J$ Clin Invest 1988; 18: 98-104.

3 Adler G, Reinshagen M, Koop I, et al. Differential effects of atropine and a cholecystokinin receptor antagonist on pancreatic secretion. Gastroenterology 1989;96: 1158-1164.

4 Adrian TE, Besterman HS, Mallinson CN, et al. Inhibition of secretin stimulated pancreatic secretion by pancreatic polypeptide. Gut 1978; 20: 37-40.

5 Adrian TE, Bloom SR, Besterman HS, et al. Mechanism of pancreatic polypeptide release in man. Lancet 1977; 1 : 161-163.

6 Layer P. Intestinale Regulation der Pankreasenzymsekretion: Stimulatorische und inhibitorische Mechanismen. Z Gastroenterol 1992; 30: 495-497.

7 Chernick SS, Lepovsky S, Chaikoff IL. A dietary factor regulating the enzyme content of the pancreas: changes induced in size and proteolytic activity of the chick pancreas by ingestion of raw soybean meal. Am J Physiol 1948; 155: 33-41.

8 Fölsch UR, Cantor P, Wilms HM, et al. Role of cholecystokinin in the negative feedback control of pancreatic enzyme secretion in conscious rats. Gastroenterology 1987; 92: 449-458.

9 Louie DS, May D, Miller P, et al. Cholecystokinin mediates feedback regulation of pancreatic enzyme secretion in rats. Am J Physiol 1986; 250: G252-259.

10 Green GM, Lyman RL. Feedback regulation of pancreatic enzyme secretion as a mechanism for trypsin-inhibitoryinduced hypersecretion in rats. Proc Soc Exp Biol Med 1972; 140: 6-12.

11 Ihse I, Lilja P, Lundquist I. Trypsin as a regulator of pancreatic secretion in the rat. Scand J Gastroenterol 1979; 13: 873-880.

12 Levan VH, Green GM. Effect of diversion of bile-pancreatic juice to the ileum on pancreatic secretion and adaptation in the rat. Proc Soc Exp Biol Med 1986; 181: 139-143.

13 Shiratori K, Chen YF, Chey WY, et al. Mechanism of increased exocrine pancreatic secretion in pancreatic juicediverted rats. Gastroenterology 1986; 91: 1171-1178. 
14 Owyang C, Louie DS, Tatum D. Feedback regulation of pancreatic enzyme secretion: suppression of cholecystokinin release by trypsin. J Clin Invest 1986; 77: 2042-2047.

15 Dlugosz J, Fölsch UR, Czaikowski A, et al. Feedback regulation of stimulated pancreatic enzyme secretion during intraduodenal perfusion of trypsin in man. Eur $J$ Clin Invest 1988; 18: 267-272.

16 Ihse I, Lilja P, Lundquist I. Feedback regulation of pancreatic enzyme secretion by intestinal trypsin in man. Digestion 1977; 15: 303-308.

17 Miyasaka K, Funakoshi A, Kitani K, et al. Inhibitory effect of pancreastatin on pancreatic exocrine secretions. Gastroenterology 1990; 99: 1751-1756.

18 Liener IE, Goodale RL, Deshmukh A, et al. Effect of a trypsin inhibitor from soybean (Bowman-Birk) on the secretory activity of the human pancreas. Gastroenterology 1988; 94: 419-427.

19 Dlugosz J, Fölsch UR, Creutzfeldt W. Inhibition of intraduodenal trypsin does not stimulate exocrine pancreatic stimulation in man. Digestion 1983; 26: 197-204.

20 Hotz J, Ho SB, Go VLW, et al. Short-term inhibition of duodenal tryptic activity does not affect human pancreatic, biliary, or gastric function. J Lab Clin Med 1983; 101: 488-495.

21 Mössner J, Secknus R, Meyer J, et al. Treatment of pain with pancreatic extracts in chronic pancreatitis: results of a prospective placebo-controlled multicenter trial. Gastroenterology 1991; 100: A290.

22 Mössner J. Therapie der chronischen Pankreatitis. Z Gastroenterol 1991; 29: 541-547.

23 Fölsch UR. Pankreasenzym-Präparate zur Schmerztherapie bei chronischer Pankreatitis. Dt Ärzteblatt 1989; 86: 604,605.

24 Funakoshi A, Nakano I, Shinozaki H, et al. High plasma cholecystokinin levels in patients with chronic pancreatitis having abdominal pain. Am J Gastroenterol 1986; 81: 1174-1178.

25 Isaksson G, Ihse I. Pain reduction by oral pancreatic enzyme preparation in chronic pancreatitis. Dig Dis Sci 1983; 2: 97-102.

26 Slaff J, Jacobson D, Tillman CR, et al. Protease-specific suppression of pancreatic exocrine secretion. Gastroenterology 1984; 87: 44-52.
27 Pieramico O, Dominguez-Muñoz E, Nelson DK, et al. Interdigestive cycling in chronic pancreatitis: altered coordination among pancreatic secretion, motility, and hormones. Gastroenterology 1995; 109: 224-230.

28 Bernfeld P. Amylases alpha and beta. Meth Enzymol 1955; 1: 149-158.

29 Hummel BCW. A modified spectrophotometric determination of chymotrypsin, trypsin and thrombin. Can J Biochem Physiol 1959; 37: 1393-1399.

30 Kemmer TP, Malfertheiner P, Büchler M, et al. Inhibition of human exocrine pancreatic secretion by the long-acting somatostatin analogue octreotide (SMS 201-995). Aliment Pharmacol Ther 1992; 6: 41-50.

31 Corring T. Mechanisme de la secretion pancreatique exocrine chez le porc: regulation par retro inhibition. Ann Biol Anim Biochim Biophys 1973; 13: 755,756.

32 Solomon TE, Petersen H, Elashoff J, et al. Interaction of caerulein and secretin on pancreatic size and composition in rat. Am J Physiol 1978; 235: 714-719.

33 Solomon TE, Morisset J, Wood JG, et al. Additive interaction of pentagastrin and secretin on pancreatic growth in rats. Gastroenterology 1987; 92: 429-445.

34 Layer P, Peschel S, Schlesinger T, et al. Human pancreatic secretion and intestinal motility: effects of ileal nutrient perfusion. Am J Physiol 1990; 258: G196-201.

35 Graham SM, Zucker KA, Adrian TE, et al. Pancreastatin: a novel regulatory peptide which inhibits pancreatic exocrine function. Gastroenterology 1988, 94: A153.

36 Schönfeld JV, Müller MK. The effect of pancreastatin on endocrine and exocrine pancreas: a review. Scand $J$ Gastroenterol 1991; 26: 993-999.

37 Owyang C, May D, Louie DS. Trypsin suppression of pancreatic enzyme secretion: Differential effect of cholecystokinin release and the enteropancreatic reflex. Gastroenterology 1986; 91: 637-643.

38 Bockman DE, Büchler M, Malfertheiner, et al. Analysis of nerves in chronic pancreatitis. Gastroenterology 1988; 94 : 1459-1469.

39 Lee PC, Newman BM, Praissman M, et al. Cholecystokinin: a factor responsible for the enteral feedback control of pancreatic hypertrophy. Pancreas 1986; 1: 335-340. 